\title{
Customized tracheal design using 3D printing of a polymer hydrogel: influence of UV laser cross-linking on mechanical properties
}

Ana Filipa Cristovão' ${ }^{1}$ David Sousa ${ }^{1}$, Filipe Silvestre², Inês Ropio ${ }^{1}$, Ana Gaspar ${ }^{1}$, Célia Henriques ${ }^{1,3}$, Alexandre Velhinho', Ana Catarina Baptista', Miguel Faustino ${ }^{1}$ and Isabel Ferreira ${ }^{1 *}$ (D)

\begin{abstract}
Background: The use of 3D printing of hydrogels as a cell support in bio-printing of cartilage, organs and tissue has attracted much research interest. For cartilage applications, hydrogels as soft materials must show some degree of rigidity, which can be achieved by photo- or chemical polymerization. In this work, we combined chemical and UV laser polymeric cross-linkage to control the mechanical properties of 3D printed hydrogel blends. Since there are few studies on UV laser cross-linking combined with 3D printing of hydrogels, the work here reported offered many challenges.

Methods: Polyethylene glycol diacrylate (PEGDA), sodium alginate $(\mathrm{SA})$ and calcium sulphate $\left(\mathrm{CaSO}_{4}\right)$ polymer paste containing riboflavin (vitamin B2) and triethanolamine (TEOHA) as a biocompatible photoinitiator was printed in an extrusion 3D plotter using a coupled UV laser. The influence of the laser power on the mechanical properties of the printed samples was then examined in unconfined compression stress-strain tests of $1 \times 1 \times 1 \mathrm{~cm}^{3}$ sized samples. To evaluate the adhesion of the material between printed layers, compression measurements were performed along the parallel and perpendicular directions to the printing lines.

Results: At a laser density of $70 \mathrm{~mW} / \mathrm{cm}^{2}$, Young's modulus was approximately $6 \mathrm{MPa}$ up to a maximum compression of $20 \%$ in the elastic regime for both the parallel and perpendicular measurements. These values were within the range of biological cartilage values. Cytotoxicity tests performed with Vero cells confirmed the cytocompatibility.

Conclusions: We printed a partial tracheal model using optimized printing conditions and proved that the materials and methods developed may be useful for printing of organ models to support surgery or even to produce customized tracheal implants, after further optimization.
\end{abstract}

Keywords: 3D printing, Biopolymer, In-situ UV laser polymerization, Mechanical properties, Tracheal 3D model

\footnotetext{
* Correspondence: imf@fct.unl.pt

${ }^{1}$ i3N/CENIMAT, Department of Materials Science, Lisbon, Portugal

Full list of author information is available at the end of the article
}

(c) The Author(s). 2019 Open Access This article is distributed under the terms of the Creative Commons Attribution 4.0 International License (http://creativecommons.org/licenses/by/4.0/), which permits unrestricted use, distribution, and reproduction in any medium, provided you give appropriate credit to the original author(s) and the source, provide a link to the Creative Commons license, and indicate if changes were made. 


\section{Background}

There are several potential health-related applications of 3D printing [1], most of which are in the field of neurosurgery [2], orthopaedics [3], spinal surgery [4], maxillofacial surgery [5], tissue engineering [6], indirect fabrication of medical devices [6], cell seeding and culturing [7], cardiac surgery $[8]$ and cranial surgery $[9,10]$, where $3 \mathrm{D}$ printing can be used to print the final implant. 3D printing can also be used as an aid in 3D models to help visualize complex medical cases, in addition to assisting student teaching and patient education also allows health professionals to practice certain procedures [1], which can be complemented by the fabrication of anatomical models for pre-surgical planning [6]. 3D printing of customized prosthetics to replace damaged regions of bones, organs, cartilage or tissue is in high demand to enable prosthesis integration. However, resolution of $3 \mathrm{D}$ printing technologies is not a limiting factor, there is a need for new biocompatible materials that can fulfil the required specificities of different applications, such as cartilage $[1,6,11]$.

Hydrogels are cross-linked networks of hydrophilic polymers, which are capable of absorbing water up to thousands of times their dry weight [12]. They are also biocompatible and can be delivered into the body through minimally invasive methods [12]. Although hydrogels are the most extensively studied materials for cartilage replacement, implants with properties that mimic natural cartilage are some way off. Several ways to obtain hydrogels in a 3D form have been reported [11]. Commonly used methods include dispensing two reactive components using mixing nozzles, inducing cross-linkage through heat or UV light $[1,6,11]$ or delivering one material to a plotting reactive medium to finish the curing reaction. Hydrogels can be fabricated in various ways, such as radiation, freeze-thawing, chemical cross-linking or thermal annealing [13]. Some examples of biocompatible hydrogels are polyethylene glycol diacrylate (PEGDA), which is a blank slate hydrogel that jellifies rapidly at room temperature in the presence of a photoinitiator and UV light. Since PEGDA gels are hydrophilic and elastic, and can be mixed with a variety of biological molecules, they constitute powerful tools for bioprinting. PEGDA gels are also biologically inert, and their mechanical properties can be adjusted over a large range of Young's moduli. Poly (vinyl alcohol) (PVA) and alginate are other hydrogels widely used in biomedical applications $[14,15]$. The mechanical properties of PVA can be enhanced by cross-linking with glutaraldehyde [14]. Alginate becomes a hydrogel when an aqueous alginate solution is mixed with divalent cations due to ionic cross-linking [15]. The blocks of guluronate in alginate chains bind to the divalent cations, and a gel structure forms by the junction of functional groups from separated polymer chains [15]. The cross-linking of hydrogels is essential to provide stability, flexibility and support the required strength of applications. That is possible when established bonds and networks are resilient to the breakage of covalent bonds.

Composite hydrogels obtained by chemical cross-linkage of polyethylene glycol (PEG) and physical cross-linkage of polyvinyl alcohol (PVA) have been investigated previously [16]. As compared with pure PVA hydrogels, which have tensile strength of only $0.17 \mathrm{MPa}$ at ultimate elongation of $312 \%$, the incorporation of chemically cross-linked PEG improves the tensile strength with the increasing PEG content [16]. There has been little research on 3D printing by extrusion of pastes combined with in situ UV laser light crosslinking or the use of riboflavin-triethanolamine (TEOHA) mixtures as photoinitiators [17]. Nguyen et al. [17] recently demonstrated the polymerization of a mixture containing PEGDA (as the polymer), riboflavin (as the photoinitiator) and TEOHA (as the co-initiator) using two-photon polymerization and a stereolithography printing technique. Pre- or postprinting cross-linking has been attempted previously. The former consists of focusing UV light on a container, usually a syringe, whereas the latter involves focusing UV light on already printed materials. However, UV light through the extrusion region requires a transparent nozzle/needle and a cross-linking variant in situ [18].

In this work, we studied the 3D extrusion of pastes containing PEGDA, sodium alginate (SA) and a photoinitiator (B2VT) consisting of a solution of riboflavin and TEOHA using a UV laser coupled to a syringe that contained the polymer mixture to be printed. This work focused on the influence of laser power on the mechanical properties of the printed samples and its optimization. In the approach applied, after each hydrogel printed layer, the UV laser scanned the printed region at the same speed as the paste extrusion. A 3D model of a trachea was printed under optimized conditions, including a segment of a life-sized trachea. This work demonstrates that it is possible to print models that can be used as an aid to surgery and to print customized implants after further improvements and studies.

\section{Materials and methods}

\section{Ink preparation}

Ink gels for 3D printing were prepared by mixing 10.8 $\mathrm{mg}$ of calcium sulphate $\left(\mathrm{CaSO}_{4}\right), 1 \mathrm{ml}$ of ultrapure water and $2.5 \mathrm{ml}$ of $34.78 \% \mathrm{wt} / \mathrm{v}$ PEGDA ( $\mathrm{Mn}=575$, Sigma-Aldrich) solution in ultrapure water, $2.5 \mathrm{ml}$ of $5 \% \mathrm{v} / \mathrm{v} \mathrm{SA}$ (90.8\%, Biochemica) solution in ultrapure water and $1 \mathrm{ml}$ of B2VT solution. $\mathrm{CaSO}_{4}$ was weighed before the addition of $1 \mathrm{ml}$ of ultrapure water and $2.5 \mathrm{ml}$ of the PEGDA solution under constant stirring. Subsequently, while maintaining stirring, $2.5 \mathrm{ml}$ of the $\mathrm{SA}$ solution were added to enhance cross-linkage of the blend. 
Finally, the B2VT solution was added to absorb UV radiation, and the mixture was loaded into a $20 \mathrm{cc}$ syringe and left to rest in an upright position for up to $12 \mathrm{~h}$ until the liquid became gel like. The B2VT solution $(10 \mathrm{ml})$ was prepared as follows: $9.5 \mathrm{mg}$ of riboflavin (98\%, Sigma-Aldrich), $3.1 \mathrm{~g}$ of TEOHA (98\%, Sigma-Aldrich) and $10 \mathrm{ml}$ of ultrapure water. The materials were placed in separate containers and weighed. Ultrapure water $(5$ $\mathrm{ml}$ ) was then added to each container under magnetic stirring. Both solutions were kept at room temperature. After stirring for $30 \mathrm{~min}$, the two solutions were mixed together and stirred for another $30 \mathrm{~min}$.

\section{Printing procedure}

A home-made 3D plotter was built [19] by integrating a syringe controlled by compressed air and a UV laser (3.8 W laser head, JTech Photonics) of variable power up to a maximum of $3.8 \mathrm{~W}$. The printing process was performed sequentially, with a printed paste layer followed by laser scanning at the same speed as the printing paste extrusion $(15 \mathrm{~mm} / \mathrm{s})$ and the same line width $(0.3 \mathrm{~mm})$, with intensities in the range of 0.4 to $2.0 \mathrm{~W}$. A $20 \mathrm{cc}$ syringe with a $0.3 \mathrm{~mm}$ needle was used with a pressure of $1.8 \mathrm{bar}$. The samples were designed using Blender and Cura 2.4.0, which created a G-code file that was later read by the printer. In this file, the laser power was determined by a number between 0 and 255 , which corresponded to a power range between 0 and $3.8 \mathrm{~W}$. The laser emission wavelengths were in the range of 435 to $455 \mathrm{~nm}$, which included one UV-Vis absorption peak of PEGDA/B2VT [20]. Figure 1 shows an image of the laser used and an example of the laser scribing a piece of wood at the maximum power of 3.8 W (Fig. 1a). Figure 1b shows the movement of the syringe and that of the laser in parallel during the printing process, and Fig. 1c shows the syringe used. Examples of the samples produced for mechanical tests are shown in Fig. 1d. The selected extrusion air pressure and printing parameters shown were optimized previously to obtain denser printing for the blend used according to the size of the syringe and characteristics of the step motors of the printer. The mechanical compression as a function of the laser power were examined while maintaining all other printing parameters at optimized settings.

To print a 3D tracheal model, data from an undisclosed patient's computed tomography $(\mathrm{CT})$ scan were used. The information retrieved from the scan was rebuilt through the files in $\mathrm{DICOM}^{\circ}$ (Digital Imaging and Communications in Medicine) format and saved in.stl format, used for $3 \mathrm{D}$ printing, and converted into G-code, the language that gives all the instructions to $3 \mathrm{D}$ printer. This final file was saved in a .gcode format using Cura 2.4.0. The .gcode file was then altered using software developed to incorporate a UV laser scan between each printed layer. This enabled

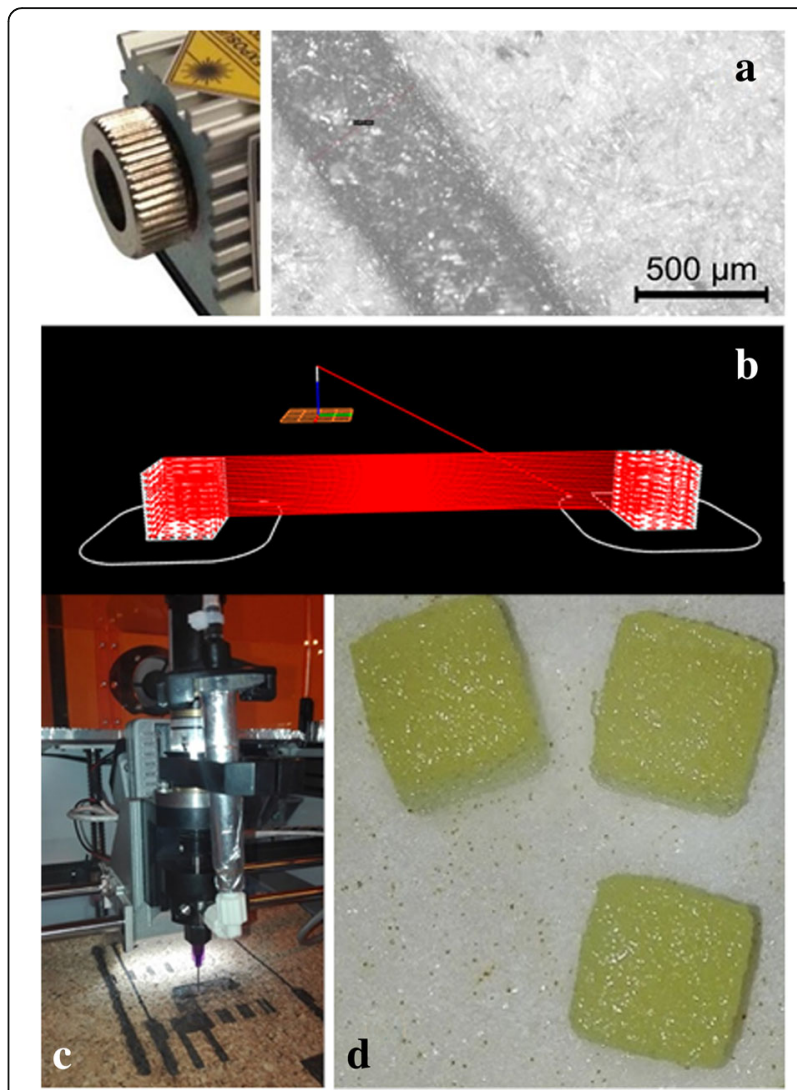

Fig. 1 a Photo of the UV laser used and the scribing width of groove made in a wood piece with the maximum power: $\mathbf{b}$ file (.gcode) for printing and UV laser scanning: c photograph of printer; $\mathbf{d}$ and example of printed samples for compression tests $\left(1 \times 1 \times 1 \mathrm{~cm}^{3}\right)$

each layer to be reticulated and vulcanized to the layer beneath. Examples of the .gcode images created are shown in Fig. 2, with different views (top, front and top). The yaxis of the laser was offset by $-70 \mathrm{~mm}$ to ensure it was in focus. The .gcode files were saved to a memory card, which was then placed in the printer's computer. The objects were printed by extrusion and left to dry until completely solid.

\section{Mechanical tests}

Unconfined compression tests were performed on printed dried samples $\left(1 \times 1 \times 1 \mathrm{~cm}^{3}\right)$ using a Shimadzu AG-50 kNG mechanical testing machine at $0.5 \mathrm{~mm} / \mathrm{min}$. The material was placed between two parallel steel plates. Perpendicular $(\perp)$ and parallel $(/ /)$ tests were then conducted in which a uniaxial force was applied perpendicular or parallel to the printed layers. At each laser power, a set of between five and seven samples were tested. A section of each sample was measured before and after the tests using a digital calliper. The load was applied to the samples until the strength started to decrease. The compressive force versus the sample height change was taken as representing the 

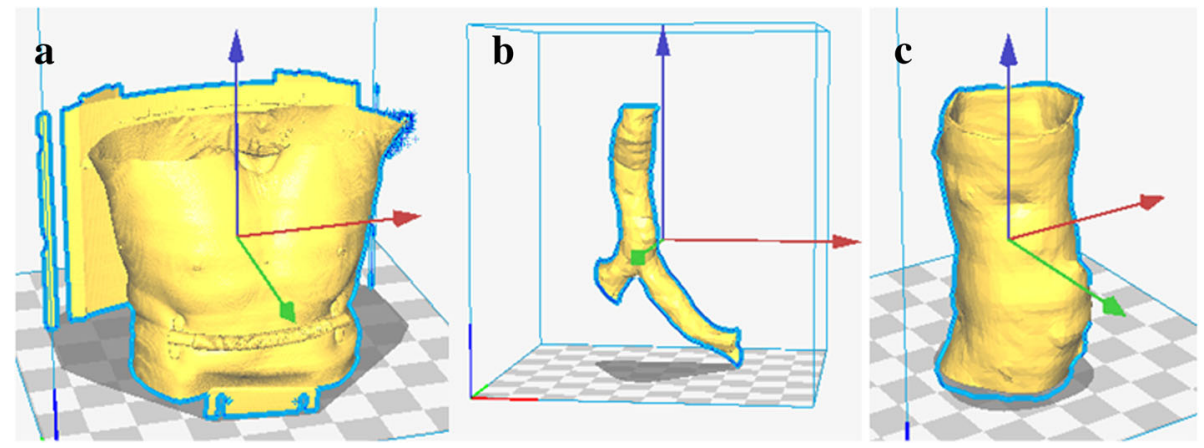

Fig. 2 3D models in .stl format based on the patient's CT scan: a initial model received; b model after some modifications; c model ready to print

true stress/strain value in accordance with previous research [21].

\section{Cytotoxicity tests}

Cytotoxicity studies were performed using African green monkey kidney epithelial cells, known as Vero cells. The cells were cultured in Dulbecco's Modified Eagle's Medium (catalogue \# D5030 Sigma-Aldrich), supplemented with GlutaMAX (\#35050-038), 10\% v/v fetal bovine serum (\#10270106), $100 \mathrm{units} / \mathrm{mL}$ of penicillin and $100 \mu \mathrm{g} / \mathrm{mL}$ of streptomycin (\#15140122), all from Life Technologies. Then, $12 \mathrm{k}$ cells were seeded per well in a 96-well plate. All procedures were performed inside a biological safety cabinet (ESCO Labculture class II). Cultures were incubated at $37^{\circ} \mathrm{C}$ in a $5 \%$ carbon dioxide humidified atmosphere incubator (SANYO MCO-19AIC (UV)).

In the cytotoxicity assay, the extract method was used according to International Standard ISO 10993-5. The tested samples were weighed, sterilized by immersion in an aqueous solution of ethanol $70 \% \mathrm{v} / \mathrm{v}$, left to dry and irradiated under UV light $(254 \mathrm{~nm})$ for $30 \mathrm{~min}$. Each sample was placed in a sterilized tube to which culture medium was added in a proportion of $10 \mathrm{mg} / \mathrm{mL}$. The samples were kept immersed at $37^{\circ} \mathrm{C}$ for $24 \mathrm{~h}$. The cell culture extracts were removed and used to replace the medium in the wells containing seeded $24 \mathrm{~h}$ earlier. Negative (viable cells) and positive (cells in a cytotoxic environment) controls were established by culturing cells with culture medium and culture medium with $20 \%$ DMSO, respectively. Five replicas of each condition were used. The cells were then incubated with the extracts for $24 \mathrm{~h}$, after which a colorimetric viability assay was performed. The media in the culture wells were replaced by culture medium with $10 \%$ resazurin (Alfa Aesar) solution $(0.2 \mathrm{mg} / \mathrm{mL}$ in phosphate buffered saline), and the cells were incubated for $3 \mathrm{~h}$. Resazurin, a blue dye $(\lambda \mathrm{abs}=601 \mathrm{~nm})$, was reduced by dehydrogenase enzymes in metabolically active cells, given rise to resorufin, which had a pink colour $(\lambda$ abs $=571 \mathrm{~nm})$. The absorbance measured at $570 \mathrm{~nm}$, using a reference wavelength of $600 \mathrm{~nm}$ (Biotex ELX 800UV microplate reader), corrected by the medium control, was considered proportional to cell viability. The relative viability under the tested conditions was deduced by the ratio of the absorbance measured for that condition and the absorbance of the negative control. The combined standard uncertainty was calculated by propagation of uncertainties.

\section{Results}

The stress-strain curves obtained from the compression tests performed perpendicularly to the printing plane, using two parallel flat contact surfaces and cubic samples $\left(1 \times 1 \times 1 \mathrm{~cm}^{3}\right)$ with planar side walls are illustrated in Fig. 3. For simplicity, only three samples are shown, as these represent the curves obtained for the other samples and those obtained for the parallel measurements. The stress values in the linear region of the curve, where the yield strength was measured, are represented on the left axis, whereas the right axis corresponds to the stress values for the entire curve.

In the case of additive manufacturing, the 3D sample was obtained by stacking layers over layers of material. Thus, adhesion between the layers constrained the mechanical properties. In the fabrication process used herein, the printing conditions were set to obtain maximum density with the selected blend, and cross-linking was obtained using a UV laser that scanned the printed layer just after extrusion, while following the same trajectory of the extruder nozzle. The gel printing followed by the UV laser scanning process was first verified by printing one, two or more layers to determine whether the hydrogel maintained three dimensions; the colour changed from transparent to white, thereby indicating that cross-linkage occurred; and the hydrogel could be removed from the substrate and handled without breaking (Additional file 1: Figure S1).

Up to around $20-25 \%$ strain, the stress $(\sigma)$ versus strain $(\varepsilon)$ curve exhibited a linear region, from which the elastic modulus or Young's modulus was determined from the 


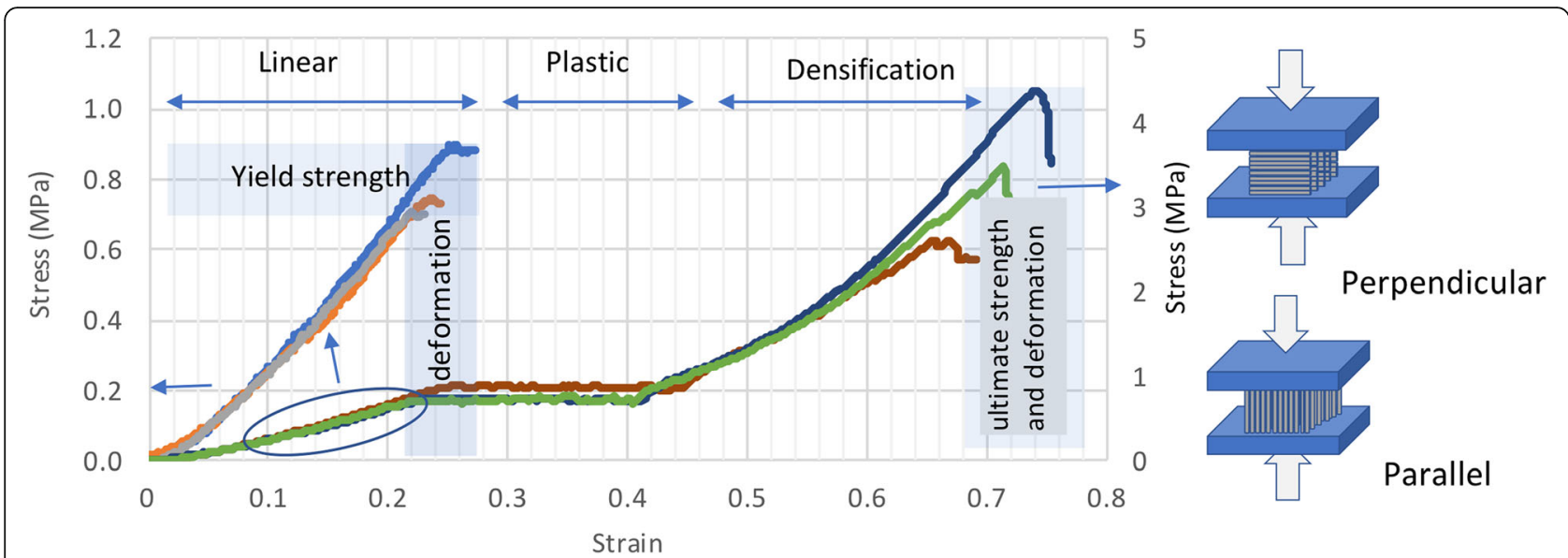

Fig. 3 Stress-strain curves for unconfined compression tests of cubes reticulated at $941 \mathrm{~mW}$ of perpendicular samples - first slope for each curve on the left axis and complete curve for each sample on the right axis. In blue are highlighted the regions where yield strength, deformation and ultimate strength and deformation were obtained while arrows represent the linear, plastic and densification regions of the curves. Beside the figure is sketched the applied force for perpendicular and parallel measurements in respect to printing lines

slope. The yield strength, respective deformation values, and maximum strength and corresponding deformation before collapse were also determined [17, 22]. The plastic deformation plateau followed the yield behaviour, in common with foams and most polymers [22]. Upon a further increase in the compression force, the material underwent densification, corresponding to a second slope in the stress versus strain curve, culminating in failure of the connection between the polymer chains at ultimate strength. The yield deformation decreased, and deformation was more pronounced when the compression force was applied perpendicularly to the plane of the printed layers (Additional file 1: Table S1).

The average mechanical parameters (i.e. Young's modulus, yield strength and ultimate compressive strength) obtained from the measurements of the five different samples in the parallel and perpendicular compression tests as a function of the laser power are shown in Fig. 4. A top view and cross-section SEM image of the $0.9 \mathrm{~W}$ samples are shown in Fig. 5a and b, respectively. The effect of increasing the laser intensity is shown in Fig. $5 c$, where a failure region perpendicular to the printing lines can be seen.

Cell viability was used as an indicator of cytotoxicity and assessed using the resazurin reduction test. Figure 6 shows the relative viability of cells exposed to an extract of a sample cross-linked at laser power of $800 \mathrm{~mW}$. The results obtained for the extracts of samples produced under other laser powers were similar to those obtained at $800 \mathrm{~mW}$. The cell viabilities obtained in the negative control (viable cells) and positive control (cells exposed to a cytotoxic environment comprising culture medium with 20\% DMSO) are displayed in Fig. 6. Based on the findings, we conclude that the viability of cells incubated with the extracts and the negative control was the same. This result points to the absence of leached cytotoxic compounds from the samples.

The original files of the patient's trachea model are shown in Fig. 2. The file was modified in Blender, software used for creating 3D models (Fig. 7). The 3D printing of a tracheal segment is shown in Fig. 8.

\section{Discussion}

In the present work, there were only small differences between the stiffness values of printed samples determined in both the perpendicular and parallel compression tests. Thus, Young's modulus can be considered to be almost isotropic and independent of the laser power, suggesting that a homogeneous polymer mixture and cross-linking were achieved at laser power in the range of $400-1600 \mathrm{~mW}$. Outside this range (below $400 \mathrm{~mW}$ ), it was impossible to obtain a solid object, and cross-linking of PEGDA was incomplete. Consequently, the gel spread when the layers were superposed.

Laser power above $1700 \mathrm{~mW}$ led to brittle 3D samples. High laser energy caused point defects or glass transition of the polymers, which resulted in fragile regions in the samples at the site of failure, leading to a marked decrease in yield strength. Laser power in the range of $600-1000 \mathrm{~mW}$ was optimum for maximizing the mechanical properties and cross-linking of the layers. Uniform and isotropic $\mathrm{E}$ values of 6-7 $\mathrm{MPa}$ and yield strength of $0.7-0.8 \mathrm{MPa}$ were obtained within this power laser range. Above this laser power, the maximum strength decreased on average, and the difference between the parallel and perpendicular values increased. The linear deformation reached $20 \%$ at laser power up to $900 \mathrm{~mW}$ but 

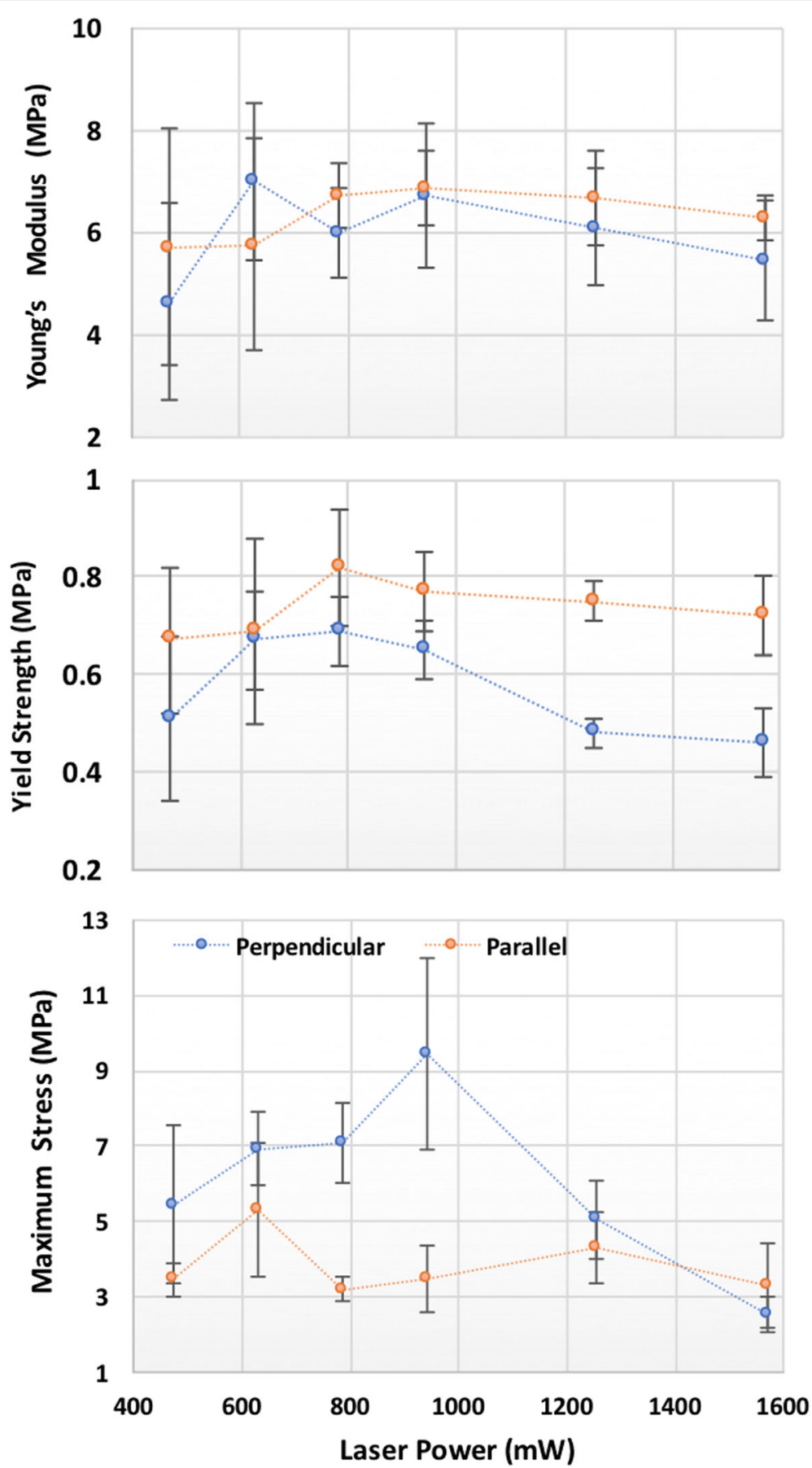

Fig. 4 Yield strength, Young's modulus and maximum strength for parallel and perpendicular compression tests as a function of UV laser power. The error bar represents the measurements standard deviation (STD)

decreased to $15 \%$ or lower at higher laser powers. Contrary to the stiffness values, the ultimate strength showed anisotropy between the parallel and perpendicular measurements. When stress was applied parallel to the layers, the weak region of the samples was the layers' junction. Thus, when the deformation force was perpendicular to the layers, layer detachment can occur, and the maximum power is affect by the interpenetration and cross-linkage between the printed lines. When these were sufficiently strong, isotropy was solely dependent upon the porosity of the material. However, the variation of perpendicular and parallel strength in the range of $600-1000 \mathrm{~mW}$ was smaller than that observed at a laser power output above $1600 \mathrm{~mW}$. 

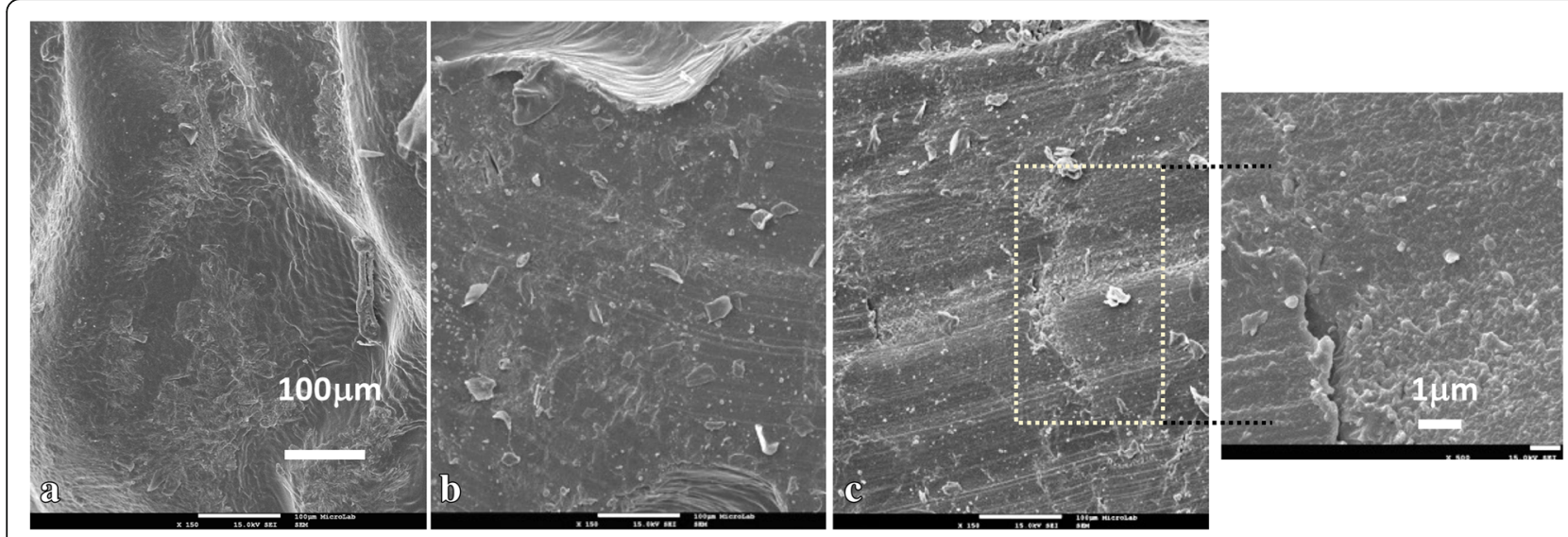

Fig. 5 SEM images of samples produced with UV laser power of: 0.9 W- a top view and $\mathbf{b}$ cross section; $1.6 \mathrm{~W}$ - c cross section

The optimized laser power of $600-1000 \mathrm{~mW}$ corresponded to a power density of $42-70 \mathrm{~mW} / \mathrm{cm}^{2}$.

In this study, we focused on the mechanical properties of PEGDA, SA and a B2VT mixture with a fixed composition the one that have shown the better gelation properties when extruded by a syringe. Bashir et al. [23] reported a decrease in the elastic modulus from $500 \mathrm{kPa}$ to $5 \mathrm{kPa}$ when the molecular weight of PEG increased from $0.7 \mathrm{kDa}$ to $10 \mathrm{kDa}$ in PEGDA hydrogels printed using a stereolithography technique. Rennerfeldt et al. [21] studied the influence of different percentages of PEGDA (10, 20 and 30\%) and three molecular weights $(2 \mathrm{kDa}, 3.4 \mathrm{kDa}$ and $6 \mathrm{kDa})$ in mechanical compression tests of mould-produced samples containing 0, 2 and 5\% agarose. Samples of 0\% agarose showed maximum stress of $3 \mathrm{MPa}$ with 20\% PEGDA and a molecular weight of 6 $\mathrm{kDa}$, and the variation in maximum strain was almost independent of the percentage of PEGDA, with increases from 0.6 to 1 when the molecular weight increased from $2 \mathrm{kDa}$ to $6 \mathrm{kDa}$. Duan et al. [24] described a 3D printed alginate/gelatin hydrogel in a 3D grid of lines about 1 to $2 \mathrm{~mm}$ apart. In their study, the ultimate tensile strength of the hydrogel decreased from $0.84 \mathrm{MPa}$ to $0.12 \mathrm{MPa}$ strength, and the elastic modulus decreased from 1.44 to $0.99 \mathrm{MPa}$ after $24 \mathrm{~h}$ of production but remain unchanged for 7 days. Yasar and Inceoglu [25] studied mechanical compression properties of PEGDA rods made by moulds and UV photopolymerization. In their study, Young's modulus increased from 3.1 to $57 \mathrm{MPa}$, and maximum strength increased from 0.5 to $10 \mathrm{MPa}$ in accordance with changes in the percentages of PEGDA in water from 20 to $100 \%$. In a recent study on the mechanical strength of alginate/poly (acrylamide-co-acrylic acid)/ $\mathrm{Fe}^{3+}$ (SA/P (AAmco-AAc $\left./ \mathrm{Fe}^{3+}\right)$, the authors reported tensile strength and strain values of $3.24 \mathrm{MPa}$ and $1228 \%$, respectively [26]. Eu-containing poly (vinyl acetate) and PVA triple physical cross-linked hydrogels exhibited $2 \mathrm{MPa}$ of compressive stress [27]. GelMA hydrogels with a compressive modulus of $288.24 \pm 62.34 \mathrm{kPa}$ and Young's modulus of $264.74 \pm$ $11.08 \mathrm{kPa}$ at $25^{\circ} \mathrm{C}$ have also been reported [28]. A wood

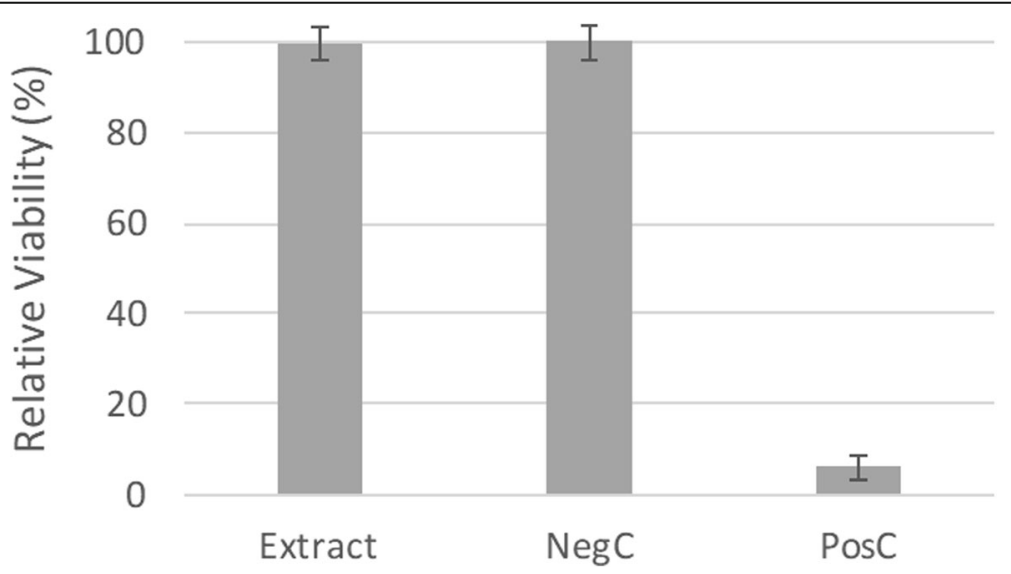

Fig. 6 Results of the cytotoxicity assay: relative viability of Vero cells incubated with extract, culture medium (NegC) and culture medium with 20\% DMSO (PosC) 


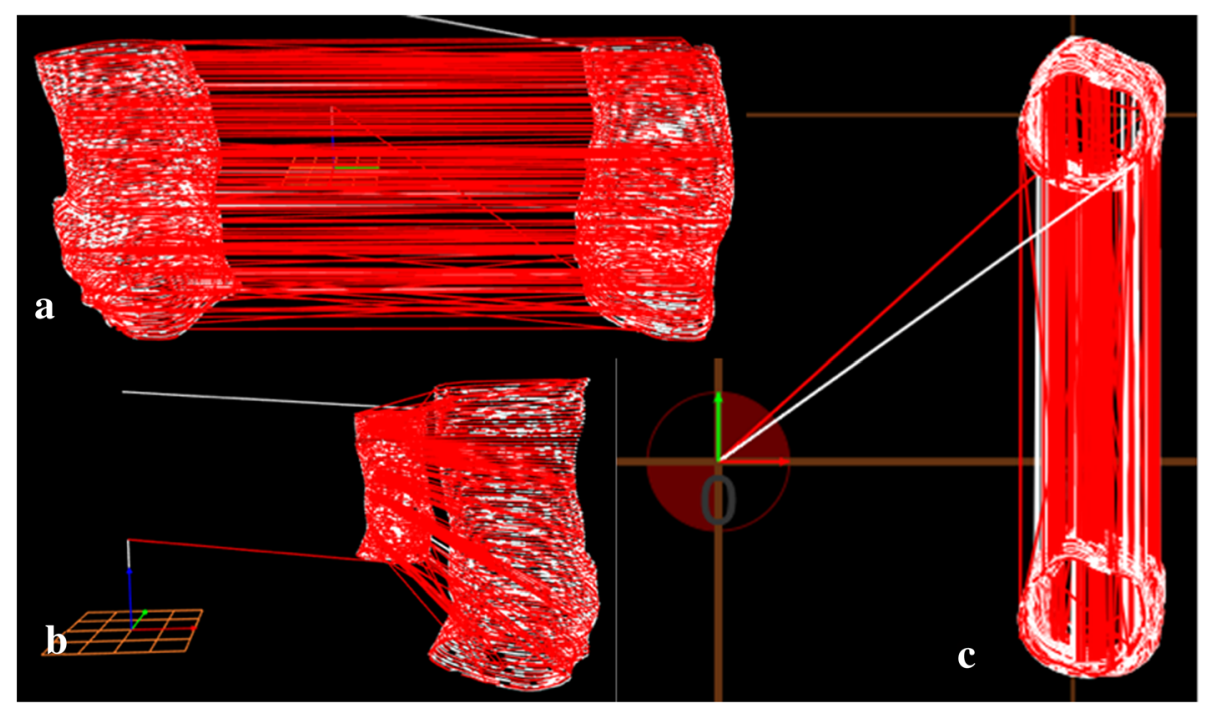

Fig. 7 3D models in .gcode format with intercalated laser layers: a view from the right; $\mathbf{b}$ front view; c top view

hydrogel with $65 \mathrm{wt} \%$ of water weight content showed significantly improved fracture tensile strength and Young's moduli of 36 and $310 \mathrm{MPa}$ in the plane of the wood fibres, and 0.54 and $0.135 \mathrm{MPa}$ in the perpendicular plane to the fibres [29].

State of the art hydrogels made by $3 \mathrm{D}$ printing techniques [30] clearly show that their mechanical properties are enhanced by cross-linking, which can be achieved by various methods, such as temperature, chemical reactions or photopolymerization. Cross-linking using photopolymerization requires the use of a photoinitiator. The main advantages of this method are the rapid formation of a hydrogel under room temperature and tuning of the cross-linking reactions by the light exposition time and intensity $[13,31]$. Furthermore, only the radiated areas are cross-linked,

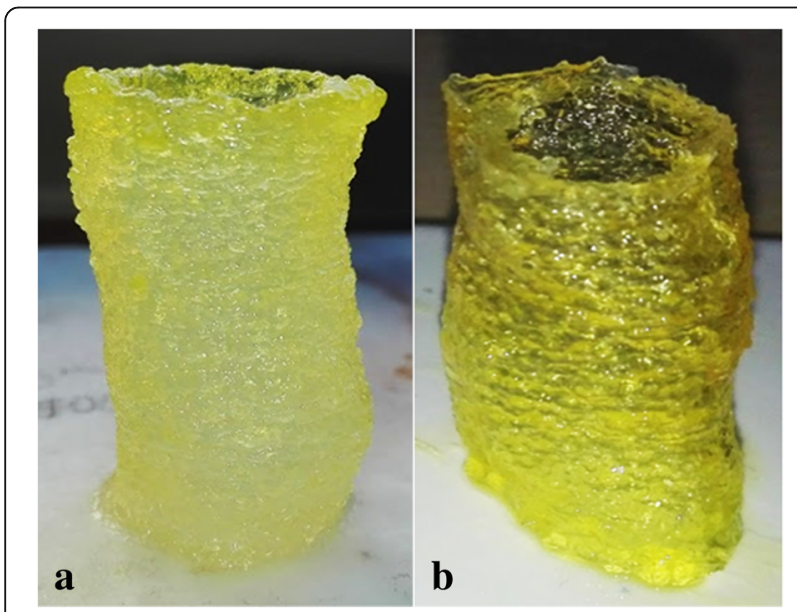

Fig. 8 Tracheal section 3D printed with simultaneous UV reticulation: a right after printing (height $=38.5 \mathrm{~mm}$, width $=19.24 \mathrm{~mm}$, thickness $=0.5$ $\mathrm{mm}$ ) and $\mathbf{b}$ after $72 \mathrm{~h}$ which allows the construction of hydrogels with complex geometries and structures [13,31]. The double bonds of unsaturated groups of some compounds, such as (meth) acrylates, are highly reactive, and excitation with light promotes radical chain-growth polymerization. Examples are reactions of hydroxyl, carboxyl and amino groups of water soluble polymers with acryloyl chloride, glycidymethacrylate forming vinlyl groups [32]. For biomedical applications, the photoinitiator must be cytocompatible. The photoinitiators Irgacure [33], riboflavin [17] and eosin [34] absorb radiation in the UV range of $250-370 \mathrm{~nm}$ and visible range of $405-550 \mathrm{~nm}$. As UV radiation exposure is considered dangerous to DNA [35], a photoinitiator absorbing in the visible range is preferable for cross-linking of hydrogels containing cells. Thus, we used B2T2 in our experiments and added $\mathrm{CaSO}_{4}$ to in the gel mixture in an attempt to increase the efficiency of cross-linkage of PEGDA. Park et al. [36] reported a beneficial effect of $0.1 \mathrm{M} \mathrm{CaCl}_{2}$ and $\mathrm{Na}_{2} \mathrm{HPO}_{4}$ on the reduction of temperature and gelation time of a methycellulose hydrogel. A recent research work also showed that divalent cations, such as $\mathrm{Ca}^{2+}$, bound to guluronate blocks of polymer chains and facilitate the junction of guluronate blocks of adjacent polymer chains. Several attempts to enhance the mechanical properties of hydrogels have been reported in the literature [37-41]. Some examples include reinforcement of alginate; gelatin hydrogels reinforced with bioglass [37] and hydroxyapatite [38]; alginate reinforced with biphasic calcium phosphate [39]; PEGDA reinforced with hydroxyapatite [40]; and PEGDA, alginate and gelatin reinforced with laponite [41].

Previous research reported that the mechanical properties of PEGDA hydrogels that mimicked cartilage were highly dependent on the fabrication process. Studies also showed that various factors, such as the UV exposure 
time, intensity and photoinitiator concentration, influenced PEGDA cross-linking and that the porosity of the film depended on the fabrication method. The surface morphology of our 3D printed samples was dense. The latter may explain the good mechanical properties of the samples. At a higher laser intensity, a failure region occurred perpendicular to the printing lines (Fig. 5c). As the compressive effort was applied along the same direction, the corresponding shear stresses generated along the print lines must have been responsible for the fracture. Thus, failure of the printed part was due to cohesive failure within each individual layer and not to adhesive failure between the different layers (layer detachment).

In the present work, the mechanical properties obtained in the compression stress tests (Young's modulus of 6-8 MPa and maximum strength of 7-11 MPa) were above the range values of biological cartilage $(1.9 \mathrm{MPa}$ Young's modulus and maximum strength of $3 \mathrm{MPa}$ ) [42]. In future work, we will investigate the influence of variations in porosity on the mechanical strength, together with fabrication parameters. In this study, all the parameters were fixed, except the laser power, and we focused only on the mechanical strength of the printed samples. Future studies will correlate the laser power with sample swelling, as the toughness of samples in contact with body fluids is very important for cartilage applications.

In the present work, several tracheal samples were printed with different wall thicknesses. As the wall thickness changed from $0.5 \mathrm{~mm}$ to $1.5 \mathrm{~mm}$, the compliance of the trachea was reduced, and it became less fragile.

\section{Conclusions}

In this study, a tracheal prosthesis was 3D printed using a UV laser cross-linking method and a PEGDA, SA and B2VT mixture. The laser power intensity was in the range of $40-70 \mathrm{~mW} / \mathrm{cm}^{2}$, and the scan speed was 15 $\mathrm{mm} / \mathrm{s}$. This resulted in optimisation of Young's modulus of around 6-7 MPa, yield strength of $0.7-0.8 \mathrm{MPa}$ and maximum strength of 7-11 MPa, which corresponded to yield deformation of $20 \%$ and $70 \%$ deformation before failure. We believe that both the polymer mixture and printing process described in this study are promising methods for creating personalized cartilage implants in the future.

\section{Additional file}

Additional file 1: Complementary information on UV cross linkage and mechanical properties. (ZIP $464 \mathrm{~kb}$ )

\section{Abbreviations}

$\mathrm{CaSO}_{4}$ : Calcium sulphate; CT: Computed tomography; DMSO: Dimethyl sulfoxide; PEG: Polyethylene glycol; PEGDA: Polyethylene glycol diacrylate;
PVA: Poly (vinyl alcohol); RF: Riboflavin; SA: Sodium alginate; TEOHA: Triethanolamine

\section{Acknowledgements}

The authors would like to acknowledge António Almeida for his support in solving electronic printer problems and Ana Sofia Pereira for her help with the experiments.

\section{Authors' contributions}

AFC prepared the inks, printed the samples and performed some of the mechanical tests, DS contributed to the formulation of the inks, FS developed the 3D printer used, and $A G$ and IR optimized the printer for the specific inks developed, $\mathrm{CH}$ performed the cytotoxicity tests, AV performed the mechanical tests, ACB and MF contributed to the experiments and the supervision of AFC, and IF was the work mentor. All the authors contributed to the preparation of the paper and the data analysis and processing. All authors read and approved the final manuscript.

\section{Funding}

This work was partially funded by H2020-ICT-2014-1, RIA, TransFlexTeg645241, which provided support for the components used in the construction of the 3D plotter; ERC-CoG-2014, CapTherPV, 647596, which provided support for the reagents, laboratory materials for he experiments, and publishing costs; FEDER through the COMPETE 2020 Program and National Funds through the FCT - Portuguese Foundation for Science and Technology under the projects UID/CTM/50025/2013, UID/QUI/50006/2013 and Pest-UID/ FIS/00068/2013, which provided support for the morphological analyses and cytotoxicity and mechanical tests.

\section{Availability of data and materials}

The datasets used and/or analysed in the current study are available from the corresponding author on request.

Ethics approval and consent to participate

No animal tests were performed.

\section{Consent for publication}

None apply.

\section{Competing interests}

The authors declare that they have no competing interests.

\section{Author details}

${ }^{1}$ i3N/CENIMAT, Department of Materials Science, Lisbon, Portugal. ${ }^{2} F A B-L A B$, Lisbon, Portugal. ${ }^{3}$ i3N/CENIMAT, Department of Physics, Faculty of Science and Technology, Universidade NOVA de Lisboa, Campus de Caparica, 2829-516 Caparica, Portugal.

Received: 2 April 2019 Accepted: 12 July 2019

Published online: 02 August 2019

\section{References}

1. Tack P, Victor J, Gemmel P, Annemans L. 3D-printing techniques in a medical setting: a systematic literature review. Biomed Eng Online. 2016;15(1):115

2. Gabriele $W$, Berndt T, Peter P, Kurt H, Johannes T. Cerebrovascular stereolithographic biomodeling for aneurysm surgery. J Neurosurg. 2004;100(1):139-45.

3. Wu X-B, Wang J-Q, Zhao C-P, et al. Printed three-dimensional anatomic templates for virtual preoperative planning before reconstruction of old pelvic injuries: initial results. Chin Med J. 2015;128(4):477-82.

4. Izatt MT, Thorpe PLPJ, Thompson RG, et al. The use of physical biomodelling in complex spinal surgery. Eur Spine J. 2007;16(9):1507-18.

5. Brie J, Chartier T, Chaput C, et al. A new custom made bioceramic implant for the repair of large and complex craniofacial bone defects. J CranioMaxillofac Surg. 2013:41(5):403-7.

6. Chia HN, Wu BM. Recent advances in $3 \mathrm{D}$ printing of biomaterials. J Biol Eng. 2015;9:4-4.

7. Levato R, Webb WR, Otto IA, et al. The bio in the ink: cartilage regeneration with bioprintable hydrogels and articular cartilage-derived progenitor cells. Acta Biomater. 2017;61:41-53. 
8. Schmauss D, Haeberle S, Hagl C, Sodian R. Three-dimensional printing in cardiac surgery and interventional cardiology: a single-Centre experience. Eur J Cardiothorac Surg. 2014;47(6):1044-52.

9. Rosenthal G, Ng I, Moscovici S, et al. Polyetheretherketone implants for the repair of large cranial defects: a 3-center experience. Neurosurgery. 2014;75(5):523-9.

10. Müller A, Krishnan KG, Uhl E, Mast G. The application of rapid prototyping techniques in cranial reconstruction and preoperative planning in neurosurgery. J Craniofac Surg. 2003;14(6):899-914.

11. Moroni L, Burdick JA, Highley C, et al. Biofabrication strategies for $3 D$ in vitro models and regenerative medicine. Nat Rev Mater. 2018;3(5):21-37.

12. Qin X, Hu Q, Gao G, Guan S. Characterization of UV-curable poly (ethylene glycol) diacrylate based hydrogels. Chem Res Chin Univ. 2015;31(6):1046-50.

13. Hu W, Wang Z, Xiao Y, Zhang S, Wang J. Advances in crosslinking strategies of biomedical hydrogels. Biomater Sci. 2019;7(3):843-55.

14. Figueiredo KCS, Alves TLM, Borges CP. Poly (vinyl alcohol) films crosslinked by glutaraldehyde under mild conditions. J Appl Polym Sci. 2009;111(6):3074-80

15. Lee KY, Mooney DJ. Alginate: properties and biomedical applications. Prog Polym Sci. 2012;37(1):106-26.

16. Li G, Zhang H, Fortin D, Xia H, Zhao Y. Poly (vinyl alcohol)-poly (ethylene glycol) double-network hydrogel: a general approach to shape memory and self-healing functionalities. Langmuir. 2015:31(42):11709-16.

17. Nguyen AK, Gittard SD, Koroleva A, et al. Two-photon polymerization of polyethylene glycol diacrylate scaffolds with riboflavin and triethanolamine used as a water-soluble photoinitiator. Regen Med. 2013;8(6):725-38.

18. Ouyang L, Highley CB, Sun W, Burdick JA. A generalizable strategy for the 3D bioprinting of hydrogels from nonviscous photo-crosslinkable inks. Adv Mater. 2017;29(8):1604983.

19. Silvestre FAA. Development of a multi-material 3D printing system with integrated post-production processes. MSc. in Materials Science Eng. FCT-UNL; 2017.

20. Faridmehr I, Osman MH, Adnan AB, Nejad AF, Hodjati R, Azimi M. Correlation between engineering stress-strain and true stress-strain curve. Am J Civ Eng Archit. 2014;2(1):53-9.

21. Rennerfeldt DA, Renth AN, Talata Z, Gehrke SH, Detamore MS. Tuning mechanical performance of poly (ethylene glycol) and agarose interpenetrating network hydrogels for cartilage tissue engineering. Biomaterials. 2013;34(33):8241-57.

22. Ashby MF. The properties of foams and lattices. Philos Trans R Soc A Math Phys Eng Sci. 2006;364(1838):15-30.

23. Chan V, Zorlutuna $\mathrm{P}$, Jeong JH, Kong H, Bashir R. Three-dimensional photopatterning of hydrogels using stereolithography for long-term cell encapsulation. Lab Chip. 2010;10(16):2062-70.

24. Duan B, Hockaday LA, Kang KH, Butcher JT. 3D bioprinting of heterogeneous aortic valve conduits with alginate/gelatin hydrogels. J Biomed Mater Res A. 2013;101A(5):1255-64.

25. Yasar O, Inceoglu S. Compressive Evaluation of Polyethylene (Glycol) Diacrylate (PEGDA) for Scaffold Fabrication. (49903), V002T003A004; 2016.

26. Li X, Wang H, Li D, Long S, Zhang G, Wu Z. Dual ionically cross-linked double-network hydrogels with high strength, toughness, swelling resistance, and improved 3D printing Processability. ACS Appl Mater Interfaces. 2018;10(37):31198-207.

27. Zhi H, Fei X, Tian J, et al. A novel high-strength photoluminescent hydrogel for tissue engineering. Biomater Sci. 2018;6(9):2320-6.

28. Yin J, Yan M, Wang Y, Fu J, Suo H. 3D bioprinting of low-concentration cellladen gelatin methacrylate (GeIMA) bioinks with a two-step cross-linking strategy. ACS Appl Mater Interfaces. 2018;10(8):6849-57.

29. Kong W, Wang C, Jia C, et al. Muscle-inspired highly anisotropic, strong, lonConductive Hydrogels. Adv Mater. 2018;30(39):1801934.

30. He Y, Yang F, Zhao H, Gao Q, Xia B, Fu J. Research on the printability of hydrogels in 3D bioprinting. Sci Rep. 2016;6:29977.

31. Nguyen KT, West JL. Photopolymerizable hydrogels for tissue engineering applications. Biomaterials. 2002;23(22):4307-14.

32. van Dijk-Wolthuis WNE, Franssen $\mathrm{O}$, Talsma $H$, van Steenbergen MJ, Kettenes-van den Bosch JJ, Hennink WE. Synthesis, Characterization, and Polymerization of Glycidyl Methacrylate Derivatized Dextran. Macromolecules. 1995:28(18):6317-22.

33. Williams CG, Malik AN, Kim TK, Manson PN, Elisseeff JH. Variable cytocompatibility of six cell lines with photoinitiators used for polymerizing hydrogels and cell encapsulation. Biomaterials. 2005;26(11):1211-8.
34. Park YD, Tirelli N, Hubbell JA. Photopolymerized hyaluronic acid-based hydrogels and interpenetrating networks. Biomaterials. 2003;24(6):893-900.

35. Hoeijmakers JHJ. DNA damage, aging, and Cancer. N Engl J Med. 2009:361(15):1475-85.

36. Park H, Kim MH, Yoon Yl, Park WH. One-pot synthesis of injectable methylcellulose hydrogel containing calcium phosphate nanoparticles. Carbohydr Polym. 2017;157:775-83.

37. Wang X, Tolba E, Schröder HC, et al. Effect of bioglass on growth and biomineralization of SaOS-2 cells in hydrogel after 3D cell bioprinting. PLOS One. 2014;9(11):e112497.

38. Demirtaş TT, Irmak G, Gümüşderelioğlu M. A bioprintable form of chitosan hydrogel for bone tissue engineering. Biofabrication. 2017;9(3):035003.

39. Fedorovich NE, Wijnberg HM, Dhert WJA, Alblas J. Distinct tissue formation by heterogeneous printing of Osteo- and endothelial progenitor cells. Tissue Eng A. 2011;17(15-16):2113-21.

40. Zhu W, Holmes B, Glazer RI, Zhang LG. 3D printed nanocomposite matrix for the study of breast cancer bone metastasis. Nanomedicine. 2016;12(1):69-79.

41. Jin Y, Liu C, Chai W, Compaan A, Huang Y. Self-supporting Nanoclay as internal scaffold material for direct printing of soft hydrogel composite structures in air. ACS Appl Mater Interfaces. 2017;9(20):17456-65.

42. Pal S. Design of Artificial Human Joints \& organs. United States: Springer US; 2014.

\section{Publisher's Note}

Springer Nature remains neutral with regard to jurisdictional claims in published maps and institutional affiliations.
Ready to submit your research? Choose BMC and benefit from:

- fast, convenient online submission

- thorough peer review by experienced researchers in your field

- rapid publication on acceptance

- support for research data, including large and complex data types

- gold Open Access which fosters wider collaboration and increased citations

- maximum visibility for your research: over $100 \mathrm{M}$ website views per year

At BMC, research is always in progress.

Learn more biomedcentral.com/submissions 